\title{
5-Hydroxytryptamine (5-HT) in the whole-blood of patients with depressive illness
}

\author{
A. COPPEN * \\ M.D., F.R.C.Psych. \\ P. TURNER \\ B.Sc., M.D., F.R.C.P. \\ A. R. RowSELL \\ M.B., B.S., F.R.C.S. \\ Cheryl Padgham \\ M.Sc. \\ * Medical Research Council Neuropsychiatry Laboratory, West Park Hospital, Epsom, Surrey, and \\ Department of Clinical Pharmacology, St Bartholomew's Hospital, London E.C.2.
}

\begin{abstract}
Summary
Whole-blood 5-HT was examined in thirty-five depressive patients not on antidepressants, and in comparable control subjects. The concentration of whole-blood 5-HT was significantly lower during depression, but returned to normal after clinical recovery.
\end{abstract}

\section{Introduction}

Many, but not all, investigations point to a decrease in 5-hydroxytryptamine (5-HT) synthesis in depressive illness (Coppen, 1972; Lapin and Oxenkrug, 1969). Thus, the concentration of brain 5-hydroxyindole acetic acid (5-HIAA) has been reported decreased in the brains of depressive suicides (Shaw, Camps and Eccleston, 1967; Bourne et al., 1966; Pare et al., 1969). The concentration of 5-HIAA in lumbar cerebrospinal fluid in depressive patients has been reported decreased both before and after the administration of probenecid (Coppen et al., 1972; Ashcroft et al., 1966; Van Praag, Korf and Puite, 1970; Sjöström, 1974).

The value of many of these investigations is limited by the difficulties in providing well controlled experiments because of the obvious difficulties in obtaining a random sample of healthy subjects of comparable age and sex for either the post-mortem studies or the cerebrospinal fluid studies. More recently the authors have been examining the concentration of free plasma-tryptophan which is an important factor in determining the concentration of brain tryptophan (Tagliamonte, Biggio and Gessa, 1971). The concentration of brain tryptophan is an important factor in determining the rate of brain 5-HT synthesis as the enzyme tryptophan hydroxylase is not normally saturated in the mammalian brain (Tagliamonte et al., 1973; Fernstrom and Wurtman, 1971). In an initial investigation (Coppen, Eccleston and Peet, 1973) free plasma-tryptophan was found to be significantly decreased in female depressive patients, although this returned towards normal after clinical recovery. These findings have been confirmed of (unpublished) in a further group of female de- $N$ pressives, and the findings have also been independently confirmed by Aylward (1973), who alsoreported a correlation between free plasma-trypto-g phan concentration and clinical improvement. If음 there is a decrease in free plasma-tryptophan, other organs than the brain synthesizing 5-HT should 3 show a decreased synthesis of this compound; 5-HT is produced in many other organs, including the gut, $\stackrel{5}{\triangle}$ kidney, liver, lungs. Most 5-HT that reaches t $\overrightarrow{8} \overrightarrow{0}$ blood stream is transported by the blood platele and little 5-HT is detectable in the blood outside the platelets. Whole-blood estimates of blood 5-HT are essentially measures of platelet 5-HT.

A study of whole blood 5-HT was undertaken to see if any change in whole body 5-HT synthesis rates $\frac{0}{\mathbb{D}}$ would be reflected in a change in blood 5-HT of patients suffering from a depressive illness.

\section{Methods}

Patients were suffering from a primary depressive illness severe enough to warrant admission to the Medical Research Council Neuropsychiatry Ward. No patient had a history of mania although many had had previous attacks of depression. Twenty-eight $\delta$ female patients and seven male depressives were $§$ studied. Details are shown in Tables 1 and 2. Most 0 had not recently been treated with tricyclic or other 3 antidepressants, or if they had, a drying-out period of $\frac{}{0}$ at least 7 days was instituted, during which time they were also given a full ward diet. A certain number of $\mathcal{N}$ patients was studied after clinical recovery, following $N$ electroconvulsive therapy, and a further group of $N$ patients was studied who were well and had been on $\sigma$ lithium prophylaxis for periods of several months. Control subjects were psychiatrically normal volunteers of roughly comparable age.

Blood was collected from patients and controls at approximately $9 \mathrm{a} . \mathrm{m}$. after overnight fasting. Whole- $\overline{0}$ blood was heparinized and frozen and subsequently 
TABLE 1. Whole blood 5-HT in female control subjects and patients before and after recovery from a depressive illness

\begin{tabular}{|c|c|c|c|c|c|}
\hline & \multirow[b]{2}{*}{ No. } & \multicolumn{2}{|c|}{ Age (years) } & \multicolumn{2}{|c|}{$\begin{array}{l}\text { Whole blood } \\
5-\mathrm{HT}(\mathrm{ng} / \mathrm{ml})\end{array}$} \\
\hline & & mean & s.e. & mean & s.e. \\
\hline \multirow{4}{*}{$\begin{array}{l}\text { Control subjects } \\
\text { Depressive patients } \\
\text { Recovered depressives } \\
\text { Recovered depressives } \\
\quad \text { (on lithium) }\end{array}$} & 27 & $44 \cdot 3$ & $1 \cdot 8$ & $171 \cdot 2$ & $9 \cdot 6$ \\
\hline & 28 & $59 \cdot 6$ & $2 \cdot 8$ & $90 \cdot 2$ & $7 \cdot 0$ \\
\hline & 7 & $59 \cdot 1$ & $4 \cdot 2$ & $147 \cdot 1$ & $13 \cdot 3$ \\
\hline & 20 & $53 \cdot 2$ & $2 \cdot 0$ & $172 \cdot 6$ & $11 \cdot 0$ \\
\hline
\end{tabular}

Controls $v$. depressive patients $t=6.85, P=<0.001$

Depressive patients $v$. recovered depressives $t=3 \cdot 65$, $P=<0.001$.

TABLE 2. Whole blood 5-HT in male control subjects and patients before and after recovery from a depressive illness

\begin{tabular}{|c|c|c|c|c|c|}
\hline \multirow[b]{2}{*}{ Group } & \multirow[b]{2}{*}{ No. } & \multicolumn{2}{|c|}{ Age (years) } & \multicolumn{2}{|c|}{$\begin{array}{l}\text { Whole blood } \\
5-\mathrm{HT}(\mathrm{ng} / \mathrm{ml})\end{array}$} \\
\hline & & mean & s.e. & mean & s.e. \\
\hline \multirow{3}{*}{$\begin{array}{l}\text { Control subjects } \\
\text { Depressive patients } \\
\text { Recovered depressives } \\
\text { (on lithium) }\end{array}$} & 31 & $48 \cdot 9$ & $2 \cdot 2$ & $131 \cdot 2$ & $8 \cdot 9$ \\
\hline & 7 & $51 \cdot 4$ & $2 \cdot 5$ & $74 \cdot 1$ & $10 \cdot 6$ \\
\hline & 10 & $50 \cdot 9$ & $3 \cdot 0$ & $180 \cdot 6$ & $14 \cdot 1$ \\
\hline
\end{tabular}

Controls $v$. depressive patients $t=2.92, P=<0.01$

Controls $v$. recovered depressives (on lithium) $t=2 \cdot 79$, $P=<0.01$

Depressive $v$. recovered depressives (on lithium) $t=5 \cdot 56$, $P=<0.001$.

measured by the fluorometric method of Ashcroft et al. (1964). The lower limit of resolution was $40 \mathrm{ng} / \mathrm{ml}$.

\section{Results}

These are shown in Table 1 and Table 2. No correlation was found between blood 5-HT and age in either controls or depressive subjects, but an interesting difference was found in that the male controls had lower whole blood 5.HT than the female controls. The age of the controls and patients were comparable.

Both male and female patients showed comparable results. Patients when depressed showed a very significant decrease in whole blood 5-HT. After clinical recovery patients' whole-blood 5-HT returned to normal whether untreated or on lithium. The male patients on lithium had higher levels than the male controls.

\section{Discussion}

The blood platelets rapidly take up recently synthesized 5-HT that enters the blood stream and these results may be related to the lowering of free plasma-tryptophan that has recently been reported (Coppen et al., 1973), as this may limit the production of 5-HT in various organs of the body. The finding, in the males at least, that lithium-treated patients have increased blood 5-HT is in keeping with the observations of Murphy et al. (1970) that lithium stimulated amine transport into platelets. A reduced uptake of 5-HT into the platelets of patients with endogenous depression has been described by Hallstrom et al. (1975), but this was not found by other workers (Shaw et al., 1971).

The results are also in keeping with earlier findings of a decreased urinary excretion of tryptamine in a carefully controlled study on depressed patients (Coppen et al., 1965). The urinary excretion of tryptamine, which probably results from tryptophan metabolism in the kidney was approximately half that of normal during a depressive illness. This also could be accounted for by a decrease in free plasmatryptophan reducing the amount of tryptophan available for metabolism by the kidney.

The findings, therefore, tend to support the notion that there is a general decrease of 5-HT synthesis in depressive patients and this may be the result of a lowered free plasma-tryptophan. The aetiological importance of these results for depressive illness remains to be elucidated although the association between free plasma-tryptophan and the REM phase of sleep that we recently reported indicates that free plasma-tryptophan may have important functional effects on the central nervous system of man (Chen et al., 1974).

\section{Acknowledgments}

We are indebted to J. Bailey for the statistical evaluation of the data. Trust.

A. R. Rowsell was in receipt of a grant from the Migraine

\section{References}

AshCroft, G.W., Crawford, T.B.B., Binns, J.K. \& MaCDougall, E.J. (1964) Estimation of 5-hydroxytryptamine in human blood. Clinica chimica acta, 9, 364.

Ashcroft, G.W., Crawford, T.B.B., Eccleston, D., Sharman, D.F., MacDougall, E.J., Stanton, J.B. \& BinNS, J.F. (1966) 5-Hydroxyindole compounds in the cerebrospinal fluid of patients with psychiatric or neurological diseases. Lancet, ii, 1049.

AyLWARD, M. (1973) Plasma tryptophan levels and mental depression in post-menopausal subjects: effects of oral piperazine-oestrone sulphate. International Research Communications System,

Bourne, H.R., Bunney, W.E., Colburn, R.W., Davies, J.O., Davis, J.M., Shaw, D.M. \& CopPen, A. (1966) Noradrenaline, 5-hydroxytryptamine and 5-hydroxyindoleacetic acid in hindbrains of suicidal patients. Lancet, ii, 805.

Chen, C.N., Kalucy, R.S., Hartman, M.K., Lacey, J.H., Crisp, A.H., Bailey, J., Eccleston, E.G. \& Coppen, A. (1974) Plasma tryptophan and sleep. British Medical Journal, 4, 564.

Coppen, A. (1972) Serotonin in the affective disorders. Journal of Psychiatric Research, 9, 163.

Coppen, A., Eccleston, E. \& Peet, M. (1973) Total and free tryptophan in the plasma of depressive patients. Lancet, ii, 60. 
Coppen, A., Prange, A., Whybrow, P. \& Noguera, R. (1972) Abnormalities of indoleamines in affective disorders. Archives of General Psychiatry, 26, 474.

Coppen, A., Shaw, D.M., Malleson, A., Eccleston, E. \& GuNDY, G. (1965) Tryptamine metabolism in depression. British Journal of Psychiatry, 111, 993.

FERNSTROM, J.D. \& WuRTMAN, R.J. (1971) Brain serotonin content: physiological dependance on plasma tryptophan levels. Science, 173, 149.

Hallstrom, C.O.S., Rees, W.L., Pare, C.M.B., Trenchard, A. \& TURner, P. (1976) Platelet uptake of 5-hydroxytryptamine and dopamine in depression. Postgraduate Medical Journal (Suppl.), 52 (in press).

LAPIN, I.P. \& OXENKRUG, G.F. (1969) Intensification of the central serotonergic processes as a possible determinant of the thymoleptic effect. Lancet, i, 132.

Murphy, D.L., Colburn, R.W., Davis, J.M. \& Bunney, W.E. (1970) Imipramine and lithium effects on biogenic amine transport in depressive patients. American Journal of Psychiatry, 127, 115.

Pare, C.M.B., Yeung, D.P.H., Price, K. \& Stacey, R.S. (1969) 5-Hydroxytryptamine, noradrenaline and dopamine in brain stem, hypothalamus and caudate nucleus of controls and patients committing suicide by coal gas poisoning. Lancet, ii, 133.

Shaw, D.M., Camps, F.E. \& Eccleston, E.G. (1967) 5Hydroxytryptamine in the hindbrain of depressive suicides. British Journal of Psychiatry, 113, 1407.

Shaw, D., SWeEney, D.A., Woodcock, N. \& BeVAN-Jones, A. (1971) Uptake and release of ${ }^{14} \mathrm{C}$-5-hydroxytryptamine by platelets in affective illness. Journal of Neurology, Neurosurgery and Psychiatry, 34, 224.

SuöströM, R. (1974) Diagnosis of manic-depressive psychosis from cerebrospinal concentration of 5-hydroxyindoleacetic $\mathbb{\nabla}$ acid. Advances in Biochemical Psychopharmacology, 11, 369.

Tagliamonte, A., Biggio, G. \& Gessa, G.L. (1971) ڤ Possible role of 'free' plasma tryptophan in controlling brain tryptophan concentrations. Rivista di Farmacologia e Terapia, 2, 251.

Tagliamonte, A., Biggio, G., Vargiu, L. \& Gessa, G.L. (1973) Free tryptophan in serum controls, brain tryptophan level and serotonin synthesis. Life Sciences, 12, 277.

van Praag, H.M., Korf, J. \& Puite, J. (1970) 5-Hydroxy- 3 indoleacetic acid levels in the cerebrospinal fluid of ir depressive patients treated with probenecid. Nature, N London, 225, 1259. 